\title{
TRANSITION SPACES
}

\author{
Daniella SZAUTER \\ University of Pécs, Faculty of Engineering and Information Technology, Department of Visual Sciences, \\ Pécs, Hungary, sz.danci27@gmail.com
}

\begin{abstract}
In order to understand transitional spaces I would like to create an in-depth study that includeshow they evolve, reviews their evolution and hierarchy, and analyses their role and importance. There are several types of transition spaces that can be distinguished, in my study I examine more specifically the transitions between the natural and built environment. In my study I wanted to put emphasis on the relationship between man and nature, furthermore the relationship between nature and architecture, this knowledge is necessary to understand these spaces.
\end{abstract}

Keywords: transition, transition spaces, architecture, nature.

\section{Transition spaces}

Our research is titled "Transition spaces" in which subject we want to examine the relationship between man and the environment. In order to understand the operation of transition spaces we wanted to carry out in-depth research to find out how these spaces were created, as well as describe their development, hierarchy and analyse their role and significance. Most of the people have lost the contact with nature and also have forgotten its importance and its positive effects on our lives. Because of this, it is important to deal with transition spaces and their investigation.

Transition is an in between state, in architecture, it is defined as a link or a connection between two (or more) enclosed spaces. An architectural space is incomplete without transition spaces. The planning and appearance of the temporary and traffic spaces as corridors, atriums and stairways are necessary when designing most of the buildings. The percentage of these spaces may depend on the function and type of building. Their functionality also varies according to the appropriate requirements of the building or the user's expectations.

Temporary spaces give us the opportunity to get closer to the natural world that we consider to be self-evident. These spaces can create connections that can be very useful, both aesthetically and functionally. With the right architectural design they can be easily used and their examination and observation can be a valuable experience for future design. [1]

"... When we see nature beautiful, we are there too, so beauty is nature and our common creation. When we view nature we are in it, as there is nature in us as viewers. "(Sándor Tavaszi)

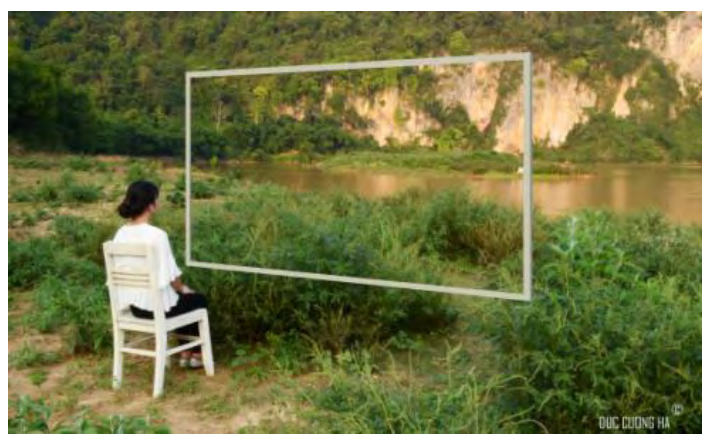

"I am convinced that we are not aware of the decisive influence our environment has built on us, which is increasingly separated from nature. This environment faces human psychic with its natural needs. The inner environment in which the unfolding of our intellectual and emotional lives is often restricted by the interior spaces. The urbanization compartment and the interior spaces in it define what I call the environment of 
man. In these spaces, negative features of harmony evolve which then become a major part of society, "writes Ferenc Nádasdy, whose statement I fully agree with.

A large percentage of people are not regularly in contact with nature. Urban people are surrounded by less and less green spaces, trees, flowers and parks. Estrangement from nature is a huge problem in our society. Nature is one of the basic pillars of our lives, so it is important to live in it with harmony. The purpose of my research is to draw attention to the estrangement between man and his environment and to highlight the importance of balancing between them, in this case the imperfection of it. In addition, I would like to find a way to solve this problem through architectural and landscape design tools that will make the individual and society closer and more environmentally aware.

In addition, the Transylvanian Way of Space Poetry was a great influence for us during the summer. During our stay we visited the lookout and resting place named Cyclops which was created in 2014 during community building. The lookout tower is located above Énlaka, on the Firtos, where we can see the village and the surrounding hills, valleys and forests. As we sat and spotted the landscape we felt some kind of calmness and we could dive into our thoughts all in harmony with nature. This meant a kind of spiritual peace that we cannot experience in the urban environment. Such and similar spaces will help us to identify the spiritual balance and get closer to the nature and identify with it.

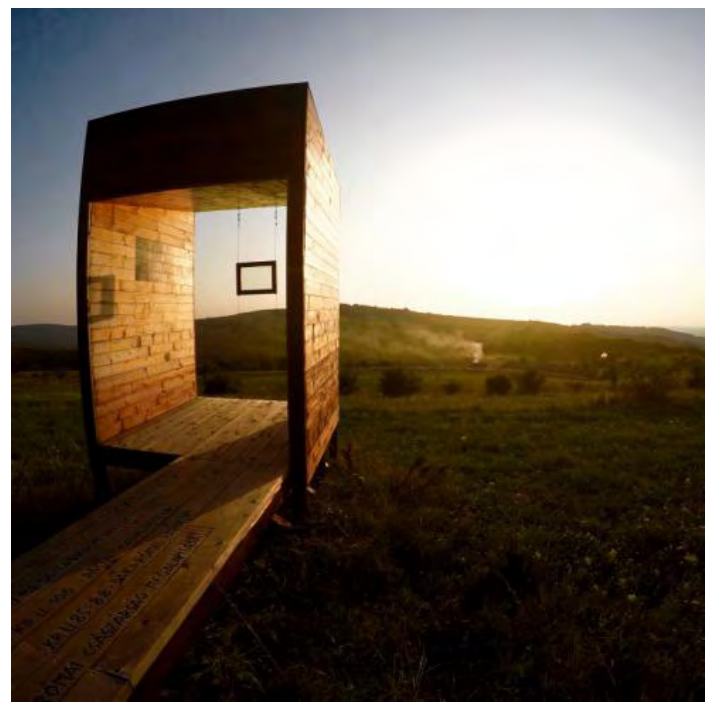

Why is the presence of nature so important in people's lives? There is now a lot of research and study dealing with the relationship between nature and man. This is a great example of Frances 'Ming' Kuo, the Illinois University's environment and behavioural research, which in my opinion is an interesting approach and a response to the question that has just been asked. With his colleagues, he explores the effects of green areas on people using different methods.

He said the following on the basis of his experience: "In a greener environment people are more generous and friendly, they maintain closer social ties with their neighbours, stronger sense of community, greater mutual trust and helpfulness, and in a less green environment the rates of aggression, violence and property are higher even if income and other factors are taken into account. Loneliness is more common and more people report inappropriate social support."

\section{Conclusions}

During the study and research of the subject, we observed that transition spaces are indispensable in design and architecture. Not just our buildings, but our public spaces and our environment would be incomplete without the existence of these spaces. Fortunately, the presence of transition spaces can be experienced almost everywhere, as they can be created without conscious planning just because of the environmental situation, so we can say that these spaces are capable of self-development. Understanding the different properties of transition spaces it can be said that this is a very interesting area. They contribute to the spatial quality of space, be it any setting or environment. Their role is functional, social, symbolic and visual, and they can serve as building blocks for sustainability.

It has also become apparent that these spaces greatly affect human behaviour, which has an impact on the design of a city or a building. At the same time people also have an impact on the properties of different urban spaces and the design of interiors as these are the main aspects in satisfying the needs of users in designing the spaces. So we can conclude that people and the surrounding physical environment are mutually shaped so that a harmonious environment can be created.

The transition spaces also appeared in the earlier ages and they were created and met the needs of the people in relation to the environment at 
that time. However, like architecture, urban design has evolved and become more and more conscious and the needs of users have changed, as a result of which transition areas have undergone changes as well and developed accordingly.

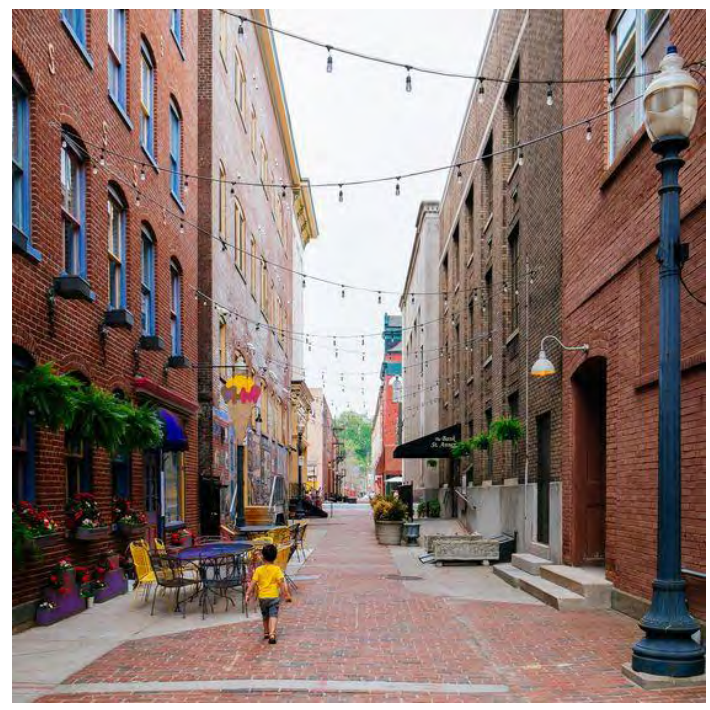

If we look at their hierarchy, the first major transition occurs at the boundary between the natural and the built environment (for example, the boundary of a forest and a city). As we move inwards into the city the next transition occurs in public spaces, streets and their intersections. Then there will be a transition between internal and external spaces, and then finally we will get to the transitions between the interiors. The transition between the natural and the built environment is also achieved on a smaller scale, either through a public space, between an interior and exterior, or even inside an interior of an atrium. Therefore, I have divided them into three groups: the first is the transition between the two places (interior-interior, outer-outer space), the second is the transition space between outer and inner spaces, and the third is the transitions between the natural and constructed environment. From these types the third was emphasized more because the understanding of the relationship between architecture, nature and architecture was indispensable for me.

Maintaining a direct relationship with nature is of great importance because we need to be in contact with it and its proximity, as it has proven positive influence on people, both mentally and physically. That is why they strive to make nature closer to their everyday lives by architectural means. At urban level this will be achieved by increasing the green areas of the public spaces, with green corridors and parks built in the city. They also intend to integrate nature into buildings, creating internal gardens, green terraces and green roofs. This applies to a more pleasant and liveable design of their homes, since we think about how much more relaxed the situation is to be in a room where we cannot see the four walls but look at an inner courtyard or garden.

It is important to put great emphasis on bringing people back into nature and strengthening their relationship with nature, as today's separation from nature is a social problem that needs to be remedied. For reconnection, there are "gates" and crossing bridges, designers create a space that will attract people's attention and make them use it. These transition spaces result in users being involved and thus leading them to nature where people can emerge according to their needs, whether it is adventure or urban congestion, distraction from the noise, and the feeling of tranquillity.

Installations in nature, smaller buildings can bring their users closer to nature, as designers use such modern design tools, structures, and approaches as designers to affect these human senses. Thus, there are buildings that create a natural effect for those who live in them, yet they find themselves in an artificial building. Such sites are a kind of harmony between artificial and natural space, giving users a transition that breaks away the general built-in experience and returns them to nature. Therefore, these spaces have a beneficial effect that can remedy the aforementioned problem.

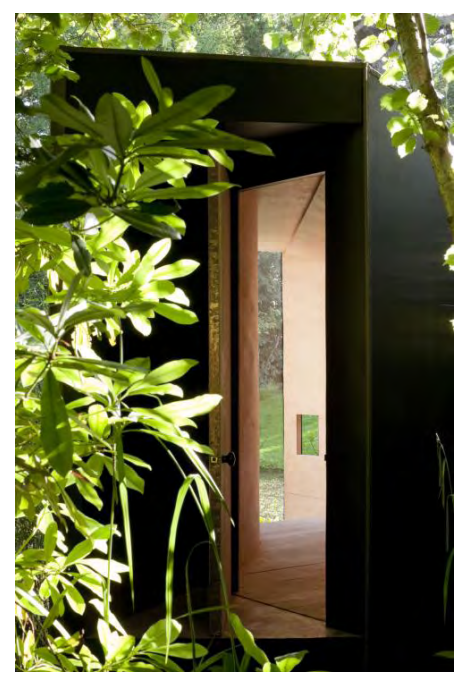




\section{References}

[1] Rashmi Singh: Understanding transition spaces. 2005

[2] Shweta Deshmukh: Transition spaces. 2009

[3] Kerékgyártó Béla (2005): Hely és jelentés. Tanulmányok az építészetröl és a városról. Terc Kereskedelmi és Szolg. Kft., 2005.

[4] Brebbia C. A.,. Pulselli R.: Eco-Architecture V. Harmonisation between Architecture and Nature. Architecture vs. nature (P. Haupt). 2014. 